\title{
LYONEL TROUILLOT, Ne m'appelle pas Capitaine
}

\section{Roberto Ferraroni}

\section{OpenEdition \\ Journals}

\section{Edizione digitale}

URL: https://journals.openedition.org/studifrancesi/32413

DOI: 10.4000/studifrancesi.32413

ISSN: 2421-5856

\section{Editore}

Rosenberg \& Sellier

\section{Edizione cartacea}

Data di pubblicazione: 1 août 2020

Paginazione: 454-455

ISSN: 0039-2944

\section{Notizia bibliografica digitale}

Roberto Ferraroni, «LYonel TROuILlot, Ne m'appelle pas Capitaine», Studi Francesi [Online], 191 (LXIV | II) | 2020, online dal 01 septembre 2020, consultato il 18 septembre 2021. URL: http://

journals.openedition.org/studifrancesi/32413 ; DOI: https://doi.org/10.4000/studifrancesi.32413

Questo documento è stato generato automaticamente il 18 septembre 2021.

\section{(2) $\odot \Theta \Theta$}

Studi Francesi è distribuita con Licenza Creative Commons Attribuzione - Non commerciale - Non opere derivate 4.0 Internazionale. 


\title{
LYONEL TROUILLOT, Ne m'appelle pas Capitaine
}

\author{
Roberto Ferraroni
}

\section{NOTIZIA}

Lyonel tRouillot, Ne m'appelle pas Capitaine, Arles, Actes Sud, 2018, 148 pp.

Come sempre accade con le opere di Lyonel Trouillot, anche con questo romanzo l'autore vuole portare alla luce alcuni aspetti della vita sull'isola di Haiti, soprattutto attraverso la caratterizzazione dei personaggi creati dalla sua penna. Riesce nel suo intento, grazie a un intelligente gioco di opposizioni da lui "cucito" sui due personaggi principali: Francis e Aude. Tutto sembra metterli in contrapposizione, come due linee perpendicolari che coesistono sullo stesso piano (Haiti), ma destinate a non incontrarsi mai: lui vecchio, povero e malato; lei giovane, ricca e bella. E invece, contrariamente a ciò che ci si potrebbe aspettare, i due si incontrano, mettendo in comunicazione le due facce della vita ad Haiti.

In un certo senso questo incontro (il lettore lo può capire solo dopo alcune pagine del romanzo) è anticipato già dal titolo, forte, decisamente particolare, che però lascia indubbiamente intendere che i protagonisti saranno almeno due. Infatti "ne m'appelle pas Capitaine", che è anche la prima frase del romanzo e che ritornerà più volte all'interno dell'opera, è un imperativo che lascia prevedere un dialogo tra due persone. Un dialogo che probabilmente non sarà del tutto semplice, dal momento che l'imperativo rappresenta un divieto per l'interlocutore. È una frase brusca, scostante, che non lascia possibilità di replica. Denota tensione, contrasto, chiusura verso l'altro. $\mathrm{E}$ non potrebbe essere altrimenti dal momento che le parti in gioco sono un anziano abitante di Morne Dédé, quartiere di Port-au-Prince roccaforte della resistenza contro la dittatura duvalierista, e una giornalista (bianca) in erba, residente nel quartiere borghese di Montagne Noire. 
3 Aude decide di intervistare Francis perché vuole costruire la sua prima inchiesta e sceglie Morne Dédé e la scuola di arti marziali fondata dal Capitaine come argomento. All'inizio il primo approccio tra i due rischia di trasformarsi in una collisione violenta, sottolineata anche dall'asprezza delle parole utilizzate, soprattutto dall'uomo. Da un lato Francis, sconsolato, arrabbiato con la vita a causa della sua povertà, della sua sofferenza, di un amore perduto che si muove sullo sfondo dell'intero romanzo come un fantasma; dall'altro una ragazza borghese, con tendenza a guardare dall'alto in basso l'altro-da-sé, ma al contempo con una curiosità e un interesse, a stento trattenuti, nello scoprire un mondo che non ha mai conosciuto davvero, dettati anche dal desiderio di ribellione nei confronti dei genitori e di una classe sociale che è disposta anche ad accettare matrimoni fra consanguinei pur di mantenere il colore candido della pelle perché un colorito "brune pêche" non sarebbe sufficientemente bianco. All'inizio sembra esserci una specie di razzismo reciproco tra i due personaggi, basato su preconcetti e pregiudizi, espresso attraverso parole rudi, soprattutto del Capitaine come quando le dice «tu ne parais pas riche, tu pues riche. C'est sur tes joues, dans tes yeux. Tu serais nue que ta richesse s'étalerait sur ta nudité» (p. 54). Tuttavia man mano che l'intervista procede, nel susseguirsi di più sedute, la distanza tra i due diminuisce progressivamente fino ad aprire un ventaglio di possibilità che li potrebbe veder collaborare fianco a fianco.

Durante la narrazione, Trouillot dà la possibilità al lettore di scoprire poco per volta alcuni segreti della vita dei due protagonisti che lo aiutano a capire meglio la psicologia di entrambi. I trascorsi di Francis sono indubbiamente più duri e gli hanno lasciato cicatrici indelebili nella mente e nel cuore. La vita di Aude è stata più semplice, anche considerata l'età; tuttavia attraverso i suoi occhi scorgiamo una classe sociale all'apparenza perfetta, ma che in realtà è marcia, corrotta, sporca e la ragazza se ne rende conto man mano che sfoglia i ricordi nella sua mente. La conversazione viene poi arricchita dalle parole di personaggi secondari che ruotano intorno a loro, come Antoine (lo zio di Aude), o come la banda di ragazzini di strada che giocherà un ruolo importante nell'evoluzione positiva che conclude il romanzo.

Lo stile dell'autore è come sempre impeccabile. Trouillot cerca di trasformare le sue frasi in musica, soprattutto quelle del Capitaine, scritte tutte rigorosamente in corsivo. Si tratta di frasi molto brevi, concise, ma con una grande forza intrinseca, che scaturisce fermamente da ogni parola. Nonostante l'atmosfera cupa e a tratti anche angosciante della prima parte, in cui a dominare è lo scontro di classe tra i protagonisti, l'autore vuole dare un chiaro messaggio di speranza per il futuro: la caduta del muro che separa Francis e Aude apre la strada a nuovi orizzonti da percorrere, a nuove possibilità che possono essere condivise nonostante la differenza sociale. 